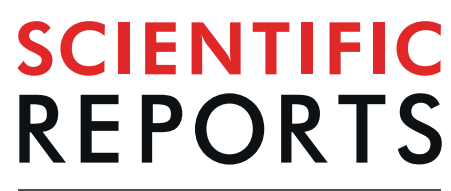

natureresearch

\title{
Effect of excessive gestational weight on daughters' breast density at the end of puberty onset
}

\begin{abstract}
Ana López ${ }^{1}$, María Luisa Garmendia ${ }^{2}$, John Shepherd ${ }^{3}$, Karin Michels ${ }^{4,5}$, Camila Corvalán² \& Ana Pereira ${ }^{2 *}$

The effect of excessive gestational weight gain (EGWG) is related to adverse health outcomes in the offspring; however, its effect on the daughters' breast density is unclear. We aimed to assess the association between EGWG and daughters' breast composition (\% of fibroglandular volume (\%FGV) and absolute fibroglandular volume (AFGV)) at Tanner stage 4 (Tanner B4)). We included 341 girls and their mothers from an ongoing cohort of low-income Chilean girls born from 2002-2003. Maternal gestational weight gain was self-reported in 2007 , and breast density by digital mammography was measured in 2010. Weight, height and breast composition by dual X-ray absorptiometry (DXA) were measured in daughters at Tanner B4. Logistic regression models were run to assess the association between EGWG and the 80th percentile of \%FGV and AFGV. Mean gestational weight gain was $13.7 \mathrm{~kg}(\mathrm{SD}=6.9 \mathrm{~kg})$. Women with pregestational overweight or obesity exceeded the recommended gestational weight gain ( $58.8 \%$ vs. $31.8 \%$, respectively). Daughters of women who had EGWG had higher levels of AFGV (OR: $2.02 ; 95 \% \mathrm{Cl} 1.16-3.53$ ) at Tanner B4, which could be explained by metabolic and hormonal exposure in utero. However, we did not observe an association with \%FGV.
\end{abstract}

High mammographic breast density $(\mathrm{BD})$ is one of the most important determinants of breast cancer (BC) risk; women with dense breasts $(\geq 75 \%)$ have a 4.6 -fold (3.6-5.9) higher risk of BC than women with non-dense breasts $(<5 \%)^{1}$. The dense tissue corresponds to epithelial and connective tissue, which is vulnerable to the effect of carcinogenetic agents and potential mutations. Studies in young populations suggest that the percent of BD is highest at young ages (end of puberty) and declines thereafter ${ }^{2}$. The total amount of dense tissue increases during puberty until the breast reaches Tanner stage 4 (B4). At B4, the \%BD is highest and subsequently decreases in breast Tanner stage 5 (B5) due to fat infiltration in the breast ${ }^{3}$.

Chile has a high prevalence of overweight and obesity during pregnancy $(60.9 \%)^{4}$; the mean gestational weight gain $(\mathrm{GWG})$ is $13.7 \mathrm{~kg}(\mathrm{SD}=7.9 \mathrm{~kg})$, and $43.6 \%$ of pregnant women experience excessive gestational weight gain $(\mathrm{EGWG})^{5}$ as defined by the 2009 Institute of Medicine (IOM) guidelines ${ }^{6}$. EGWG is associated with high birth weight (BW) and long-term consequences for the newborn, such as obesity, type 2 diabetes mellitus and cardiovascular disease $^{7-12}$. However, the relation between maternal EGWG and BD in daughters has been little explored. The Early Determinants of Mammographic Density (EDMD) study conducted in 2016 did not demonstrate an association between maternal GWG and BD in daughters (mean age at BD exam $=43$ years) ${ }^{13}$. Limited evidence has suggested that EGWG increases BC risk in the offspring; only one study published in 1998 observed that daughters of mothers who gained 11 to $15 \mathrm{~kg}$ during their pregnancy had a $50 \%$ higher risk of BC than daughters of mothers who gained less than $11 \mathrm{~kg}^{14}$, while other study did not find an association ${ }^{15}$. Additionally, epidemiologic studies suggested that for each 1 SD or $1 \mathrm{~kg}$ increase in BW, the risk of pre- and postmenopausal BC increases by 6 and 7\%, respectively ${ }^{16,17}$. BW has also been associated with BD in women; a 1 SD increase in BW $(473 \mathrm{~g})$ resulted in a $3 \%$ increase in dense tissue at age $21 \mathrm{y}^{18}$.

Understanding early determinants of breast composition during puberty could contribute to identifying risk factors that may modulate a higher BD at early ages and decrease BC risk in adulthood. To date, no study has

\footnotetext{
${ }^{1}$ Master in Nutrition Program, Institute of Nutrition and Food Technology, University of Chile, Santiago, Chile. ${ }^{2}$ Institute of Nutrition and Food Technology, University of Chile, Santiago, Chile. ${ }^{3}$ Population Sciences in the Pacific Program, University of Hawaii Cancer Center, Honolulu, Hawaii, USA. ${ }^{4}$ Department of Epidemiology, Fielding School of Public Health, University of California, Los Angeles, California, USA. ${ }^{5}$ Institute for Prevention and Cancer Epidemiology, Faculty of Medicine and Medical Center, University of Freiburg, Freiburg, Germany. *email: apereira@inta.uchile.cl
} 


\begin{tabular}{|c|c|}
\hline Girls & \\
\hline At Birth & \\
\hline Birth weight (Kg) [mean, SD] & $3.3(0.4)$ \\
\hline At B4 & \\
\hline Age (years) [mean, SD] & $11.2(0.9)$ \\
\hline Already menarche $[\mathrm{n},(\%)]$ & $88(25.8)$ \\
\hline Weight $(\mathrm{kg})[$ mean, SD] & $44.7(8.7)$ \\
\hline Height $(\mathrm{cm})[$ mean, SD] & $148(0.1)$ \\
\hline Body mass index $\left(\mathrm{kg} / \mathrm{m}^{2}\right),[$ mean, SD] & $20.2(3.3)$ \\
\hline Body mass index Z score [mean, SD] & $0.9(1.1)$ \\
\hline Nutritional Status (n, \%) & \\
\hline Underweight $[<-1 \mathrm{SD}]$ & $17(5.1)$ \\
\hline Normal $[-1 ; 1 \mathrm{SD}]$ & $151(45.1)$ \\
\hline Overweight [1;2SD] & $118(35.2)$ \\
\hline Obese $[2 ; 3 \mathrm{SD}]$ & $47(14.0)$ \\
\hline Severe obese [>3SD] & $2(0.6)$ \\
\hline Waist circumference $(\mathrm{cm})[$ mean, SD] & $71.5(8.9)$ \\
\hline Central Obesity ( $>90$ percentile) $[\mathrm{n},(\%)]$ & $53(15.5)$ \\
\hline Mothers at pregnancy & \\
\hline Mothers age at the beginning of pregnancy & $27.1(7.6)$ \\
\hline Education $[\mathrm{n},(\%)]$ & \\
\hline$<12$ years & $107(30.9)$ \\
\hline 12 years & $142(41.0)$ \\
\hline$>12$ years & $97(28.0)$ \\
\hline Parity [n, (\%)] & \\
\hline 1 living birth & $142(41.4)$ \\
\hline+1 living birth & $199(58.4)$ \\
\hline Pre-gestational nutritional status $\left(\mathrm{kg} / \mathrm{m}^{2}\right),[\mathrm{n},(\%)]$ & \\
\hline Underweight $(<18.5)$ & $17(5.0)$ \\
\hline Normal (18.5-24.9) & $207(60.7)$ \\
\hline Overweight (25.0-29.9) & $93(27.2)$ \\
\hline Obese $(\geq 30.0)$ & $24(7.0)$ \\
\hline Gestational weight gain $(\mathrm{kg})[$ mean, $\mathrm{SD}]$ & $13.7(6.9)$ \\
\hline $\begin{array}{l}\text { Gestational weight gain }(\mathrm{kg}) \text { by pre gestational } \\
\text { nutritional status [mean, SD] }\end{array}$ & \\
\hline Underweight $(<18.5)$ & $15.6(10.2)$ \\
\hline Normal (18.5-24.9) & $13.8(6.5)$ \\
\hline Overweight (25.0-29.9) & $13.4(7.3)$ \\
\hline Obese $(\geq 30.0)$ & $12.1(6.1)$ \\
\hline Gestational Diabetes Mellitus [n, (\%)] & $16(4.7)$ \\
\hline
\end{tabular}

Table 1. Characteristics of 341 girl and mother participants in this study.

evaluated the relation between EGWG and BD at puberty in the offspring. One of the major difficulties is the challenge of measuring BD in young women. Recently, dual energy X-ray absorptiometry (DXA) technology has been developed for this purpose and has been shown to be valid, reproducible and accurate (precision of 2.8\%) ${ }^{19}$ with a minimal dose of radiation; therefore, DXA can be used in young women ${ }^{20}$. Thus, by investigating a Chilean cohort of mothers and daughters, our study aimed to assess the relation between EGWG according to the 2009 IOM guidelines ${ }^{6}$ and $\mathrm{BD}$ estimated by DXA in the offspring at the end of puberty (B4).

\section{Results}

The mean age of the daughters was $11.2 \mathrm{y}$ (SD: $0.9 \mathrm{y}$ ) at the Tanner B4 visit, and $25.8 \%$ had experienced menarche at the time of the DXA visit. The mean weight of the daughters was $44.7 \mathrm{~kg}$ (SD: $8.7 \mathrm{~kg}$ ), $49.8 \%$ had excessive weight (BMI Z-score $>1 \mathrm{SD})$, the mean waist circumference was $71.5 \mathrm{~cm}(\mathrm{SD}: 8.9 \mathrm{~cm})$, and a $15.5 \%$ had central obesity. In the mothers, the mean age at pregnancy was 27.1 years (SD: 7.6), 34.2\% were overweight or obese at the start of their pregnancy, the mean GWG of the mothers was $13.7 \mathrm{~kg}$ (SD: $6.9 \mathrm{~kg}$ ), and $41.9 \%$ of the mothers gained more weight than recommended by the IOM 2009 guidelines (Table 1).

A total of $55.9 \%$ and $75 \%$ of women who were overweight or obese at the start of their pregnancy, respectively, exceeded the weight gain recommendation. However, only $31.9 \%$ of the women who started their pregnancy with a normal pre-gestational BMI exceeded the recommendation; the differences between the groups in both cases were statistically significant $(\mathrm{p}<0.05)$ (Fig. 1$)$. 


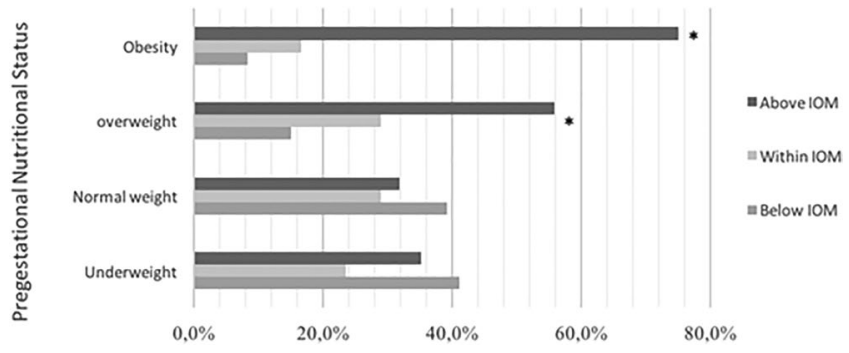

Figure 1. Adherence to IOM gestational weight gain recommendations in relation to pre-gestational nutritional status. *Statistically significant results (Fisher's test $\mathrm{p}<0.05$ ) for excessive gestational weight gain in women with pre-pregnancy BMI of overweight and obesity versus normal pre-pregnancy BMI.

In the total sample, the median \%FGV was $39.0 \%(\mathrm{IQR}=27.5-54.2)$ and the median AFGV was $79.5 \mathrm{~cm}^{3}$ $(I Q R=60.2-100.0)$. The girls who had menarche prior to the Tanner B4 visit had a significantly higher AFVG than their counterparts. The daughters of the mothers who were underweight prior to their pregnancy had a significantly lower AFGV than the daughters of the mothers with normal pre-gestational nutritional status; in contrast, the daughters of the mothers who were obese prior to their pregnancy exhibited a lower \%FGV than the daughters of the mothers in the normal pre-gestational weight category. The daughters of the mothers with GWG exceeding the IOM guideline recommendations (independent of pre-gestational nutritional status) had non-significantly higher AFGV during puberty and a lower \%FGV. Additionally, we did not observe conclusive results after stratifying by pre-gestational nutritional status, but the daughters of the women who began their pregnancy in the normal or overweight category and exceeded the recommended weight gain had non-significantly higher AFGV than the daughters of the women who met the recommendations (Table 2).

We observed a positive linear relation between GWG in kg and AFGV in the crude and adjusted models (including pregestational weight gain, girl's BMI z score at time of DXA and maternal education, breast density, parity and gestational diabetes), and even after adjusting for birth weight. The daughters of the mothers who had GWG greater than the recommendations had a 2.3-fold greater risk of having an AFGV over the 80th percentile in the adjusted models (adjusted OR: 2.27, CI 95\%: 1.17-4.40) compared to the daughters of the mothers who had a GWG below the recommendations (Table 3). Similar results were observed after further adjusting for birth weight. When comparing the daughters of mothers with EGWG vs. those of mothers with non-EGWG, we observed that the daughters of the mothers who had EGWG had a 2-fold higher risk of an AFGV over the 80th percentile in the crude and adjusted models (adjusted OR: 2.10, 95\% CI: 1.19-3.72) (Table 3). We did not observe conclusive results for \%FGV (Table 3), as well, we did not observe an association between gestational weight gain and total breast volume (data not shown in tables). BW was inversely correlated with \%FGV only in the crude analysis; we did not observe an association with AFGV (Table 3). Additionally, we repeated the analysis using AFGV and \%FGV as continuous variable. Similar results and significant results were observed between GWG in kilograms and AFGV and borderline with EGWG and AFGV; no associations with \%FGV (supplementary table S1).

\section{Discussion}

In our study, we found a positive association of absolute GWG and GWG above the recommended range of the IOM 2009 guidelines with the daughters' total AFGV, after adjusting for the girls' BMI, menarche, maternal BD, maternal education, parity, and gestational diabetes mellitus. The daughters of the mothers who had GWG above the recommendation had a twofold-increased risk of having AFGV above the $80^{\text {th }}$ percentile. We did not observe any association between GWG and \%FGV of the daughters.

To date, only one study has analyzed the effect of GWG on the BD of daughters ${ }^{13}$. The EDMD study did not observe an association of pre-pregnancy BMI or maternal GWG with \%BD or absolute dense breast tissue in the daughters. Michels et al. only revealed an increase in $\% \mathrm{BD}$ in the daughters of mothers who gained $\leq 5 \mathrm{~kg}$ during pregnancy compared with the daughters of the mothers who gained 5 to $10 \mathrm{~kg}(\beta=4.8,95 \%$ CI: 1.0 to 8.6$)$. These authors measured BD in adult women (mean age 43 years $(\mathrm{SD}=2.3)$ ); thus, BD may have been modified by known determinants of BD during the life course such as parity, age, breastfeeding, among others, while our study measured BD at Tanner B4, the time with the highest \%FGV according to the literature ${ }^{3}$. Additionally, in our study, we observed a higher prevalence of excessive pre-gestational nutritional status and overall maternal GWG [34.2\% and $13.7 \mathrm{~kg}$ (SD: $6.9 \mathrm{~kg}$ ), respectively] compared to the findings of the study conducted by Michels et al. that reported values of $25 \%$ and $9.2 \mathrm{~kg}(\mathrm{SD}=4.0)$, respectively. However contemporary follow-up studies are needed to evaluate the association between EGWG and daughter's breast cancer risk.

Two previous studies have reviewed the association between maternal GWG and the risk of BC in the offspring with divergent results. In 1998, Sanderson et al. showed a 50\% increased risk of BC in women under 45 years whose mothers gained between 11 and $15 \mathrm{~kg}$ during pregnancy (adjusted OR $=1.5,95 \%$ CI 1.1; 2.0) compared with the women whose mothers gained 6.8-10.8 kg; however, they did not observe an association between GWG greater than $15 \mathrm{~kg}$ and $\mathrm{BC}^{14}$. In 2011, using the data from NHS I and II $(\mathrm{n}=2621)$, Wilson and colleagues did not observe an association between maternal GWG and pre- and postmenopausal BC in the daughters ${ }^{15}$. However, both studies included women with a lower mean GWG compared to those included in our report. In both studies, as well as ours, maternal GWG was determined by self-report, which could have been affected by 


\begin{tabular}{|c|c|c|c|}
\hline Variable & $\mathbf{N}$ & $\% \mathrm{FGV}$ & $\operatorname{AFGV~}\left(\mathrm{cm}^{3}\right)$ \\
\hline Total & 341 & $39.0(27.5-54.2)$ & $79.5(60.2-100.0)$ \\
\hline \multicolumn{4}{|l|}{ Menarche } \\
\hline Yes & 88 & $40.2(31.6-55.4)$ & $92.6(75.0-114.2)^{*}$ \\
\hline No & 253 & $38.0(25.9-54.1)$ & $72.00(57.7-94.3)$ \\
\hline \multicolumn{4}{|c|}{ Maternal pre gestational nutritional status } \\
\hline Underweight $(\leq 18.5)$ & 17 & $45.1(37.1-52.9)$ & $63.4(52.6-72.0) \mathfrak{E}$ \\
\hline Normal weight (18.5-24.9) & 204 & $40.4(29.1-56.1)$ & $80.4(59.5-99.7)$ \\
\hline Overweight (25.0-29.9) & 93 & $36.6(26.8-52.1)$ & $80.8(62.4-105.0)$ \\
\hline Obese $(\geq 30.0)$ & 24 & $26.4(22.1-33.9) \mathfrak{E}$ & $72.8(63.8-95.6)$ \\
\hline \multicolumn{4}{|c|}{ GWG according to IOM 2009 guidelines during pregnancy } \\
\hline Above & 141 & $35.9(26.5-51.3)$ & $84.4(64.2-108.9)$ \\
\hline Within & 94 & $39.7(28.8-56.9)$ & $77.1(60.0-97.4)$ \\
\hline Below & 102 & $41.5(30.1-52.9)$ & $74.2(57.2-95.2)$ \\
\hline \multicolumn{4}{|c|}{ Adherence to IOM recommendation by pre gestational nutritional status } \\
\hline \multicolumn{4}{|c|}{ Underweight } \\
\hline - Above & 6 & $41.1(29.3-48.7)$ & $61.1(49.2-72.0)$ \\
\hline - Within & 5 & $40.1(31.7-47.6)$ & $66.2(63.5-82.8)$ \\
\hline - Below & 6 & $46.1(44.2-52.9)$ & $56.1(41.8-63.0)$ \\
\hline \multicolumn{4}{|l|}{ Normal weight } \\
\hline - Above & 65 & $40.3(28.8-57.0)$ & $86.7(65.2-108.9)$ \\
\hline - Within & 59 & $38.8(28.8-57.5)$ & $81.0(59.1-100.5)$ \\
\hline - Below & 80 & $41.8(30.6-54.3)$ & $75.0(57.4-95.8)$ \\
\hline \multicolumn{4}{|l|}{ Overweight } \\
\hline - Above & 52 & $36.0(26.3-50.8)$ & $85.0(67.6-110.6)$ \\
\hline - Within & 27 & $43.7(30.3-57.0)$ & $74.4(62.3-102.6)$ \\
\hline - Below & 14 & $33.1(25.3-49.4)$ & $74.4(62.3-95.2)$ \\
\hline \multicolumn{4}{|l|}{ Obesity } \\
\hline - Above & 18 & $26.3(22.0-35.5)$ & $74.0(64.2-95.9)$ \\
\hline - Within & 4 & $26.8(22.0-28.1)$ & $68.7(60.0-80.8)$ \\
\hline - Below & 4 & $36.2(23.9-48.5)$ & $88.0(71.1-104.9)$ \\
\hline \multicolumn{4}{|l|}{ Gestational diabetes } \\
\hline - Yes & 16 & $39.6(22.8-67.6)$ & $89.8(68.9-116.2)$ \\
\hline - No & 322 & $38.9(27.4-53.8)$ & $79.2(59.6-100.0)$ \\
\hline
\end{tabular}

Table 2. Median and Interquartile range (IQR) for breast density measures of girls in relation to study variables. * Mann Whitney test: significant differences are shown between groups $(\mathrm{p}<0.05) .{ }^{\mathfrak{E}}$ Kruskall Wallis test: normal weight category was used to compare the level of significance between the groups $(\mathrm{p}<0.05)$.

recall bias, but we expect to be a non-differential measurement error. The time between pregnancy and obtaining data on maternal GWG was shorter in the GOCs cohort ( $<10$ years), reducing measurement error.

Birth weight is a recognized risk factor for $\mathrm{BC}^{16,17}$, and women with higher GWG are more likely to have heavier offspring ${ }^{7-12,21}$. Thus, a potential pathway between GWG and BD may be mediated through BW. An EGWG will determine a hormonal environment that makes the offspring prone to higher BW, which is characterized by chronic hyperglycemia, hyperinsulinemia, and insulin resistance ${ }^{22-25}$, as well as higher levels of IGF-1 and leptin ${ }^{26-29}$. Additionally, EGWG and higher pre-gestational BMI are associated with a decrease in SBHG and an increase estrogen bioavailability ${ }^{30}$. However, we did not observe an association between BW and AFGV and only observed an association of BW with \%FGV in the unadjusted model. The relation between GWG and AFGV was not modified by including BW as an intermediate of the association (Table 3); thus, suggesting that BW was not a mediator in this association. Additionally, we did not observe an association between gestational diabetes and \%FGV or AFGV. However, the lack of association could be due to recruitment restrictions, for example, BWs $<2500$ or $>4000 \mathrm{~g}$ were excluded, thus limiting the range to detect an association and the data regarding gestational diabetes was self-reported, thus the possibility of residual confounding remained. Additionally, we did not have data of insulin levels during pregnancy. The positive association we identified between GWG and AFGV may increase BC risk in the offspring; according to Trichopoulos, the presence of IGF-1 and estrogens in the intrauterine environment increase the pool of mammary stem cells in utero, acting as mitogens independent of $\mathrm{BW}^{31,32}$.

Our study had some limitations; first, the weight before and after pregnancy was self-reported, increasing the possibility of measurement error. However, data was collected in 2007 (approx. 4 years after birth), which is a shorter time interval than those reported in other studies. Second, our recruitment excluded extreme values of BW $(<2500 \mathrm{~g}$ or $>4500)$, which could explain the lack of evidence of an association between BW and breast composition and as a consequence the results observed in this study are only representative of girls who 


\begin{tabular}{|c|c|c|c|c|c|c|c|c|}
\hline & \multicolumn{4}{|c|}{ FGV\% $80^{\text {th }}(\mathrm{OR}, 95 \% \mathrm{CI})$} & \multicolumn{4}{|c|}{ AFGV $80^{\text {th }}(\mathrm{OR}, 95 \% \mathrm{CI})$} \\
\hline & Crude model & \begin{tabular}{|l|} 
Adjusted \\
model 1
\end{tabular} & \begin{tabular}{|l|} 
Adjusted \\
model 2
\end{tabular} & \begin{tabular}{|l|} 
Adjusted \\
model 3
\end{tabular} & Crude model & \begin{tabular}{|l|}
$\begin{array}{l}\text { Adjusted } \\
\text { model } 1\end{array}$ \\
\end{tabular} & $\begin{array}{l}\text { Adjusted } \\
\text { model } 2\end{array}$ & \begin{tabular}{|l|} 
Adjusted \\
model 3
\end{tabular} \\
\hline $\begin{array}{l}\text { Gestational weight } \\
\text { gain in kg. ** }\end{array}$ & $0.97(0.94-1.01)$ & $0.99(0.95-1.03)$ & $0.98(0.93-1.03)$ & $0.98(0.93-1.03)$ & $1.04(1.01-1.07)^{*}$ & $1.05(1.01-1.08)^{*}$ & $1.06(1.02-1.10)^{*}$ & $1.06(1.02-1.11)^{*}$ \\
\hline \multicolumn{9}{|c|}{ Gestational weight gain according to IOM } \\
\hline Below & 1.00 & 1.00 & 1.00 & 1.00 & 1.00 & 1.00 & 1.00 & 1.00 \\
\hline Within & $0.85(0.49-1.50)$ & $0.76(0.36-1.60)$ & $0.67(0.28-1.60)$ & $0.68(0.28-1.66)$ & $1.02(0.57-1.83)$ & $1.17(0.63-2.15)$ & $1.26(0.62-2.58)$ & $1.38(0.66-2.86)$ \\
\hline Above & $0.58(0.34-0.98)^{*}$ & $0.75(0.38-1.48)$ & $0.68(0.30-1.53)$ & $0.69(0.30-1.66)$ & $1.76(1.04-2.97)^{*}$ & $1.84(1.06-3.20)^{*}$ & $2.27(1.17-4.40)^{*}$ & $2.47(1.24-4.92)^{*}$ \\
\hline EGWG vs not EGWG & $0.63(0.40-0.98)^{*}$ & $0.85(0.47-1.53)$ & $0.82(0.40-1.65)$ & $0.82(0.40-1.70)$ & $1.74(1.12-2.7) *$ & $1.70(1.07-2.71)^{*}$ & $2.02(1.16-3.53) *$ & $2.10(1.19-3.72)^{*}$ \\
\hline Birth weight (in kg.) & $0.52(0.30-0.91) *$ & $1.07(0.51-2.25)$ & $1.15(0.47-2.80)$ & - & $1.06(0.61-1.83)$ & $1.10(0.61-2.00)$ & $0.89(0.44-1.80)$ & - \\
\hline
\end{tabular}

Table 3. Association of Gestational Weight Gain (in $\mathrm{kg}$ and stratified by IOM), birth weight and breast composition (\%FGV, AFGV): Crude and adjusted OR and 95\%CI. *Model was statistically significant (p value $<0.05$ ). Adjusted model 1 Adjusted by maternal variables: education, parity, gestational diabetes mellitus; \& Girls variables at time B4: BMI Z score and presence of menarche). Adjusted model 2: Model 1+ maternal breast density. Adjusted model 3: Model $2+$ birth weight (in kg.). **Gestational weight gain models were adjusted by pre gestational nutritional status.

had normal birth weight. Third, even though we tried to control by potential confounders; such as, mother and girls weight, gyneco-obstetric data (parity, menarche), socioeconomic level (measured by maternal education), self-report gestational diabetes as a marker of maternal metabolic profile, we still might be in presence of residual confounding. For example, we did not have maternal metabolic data during pregnancy (insulin, IGF-1) and subclinical high glycemic levels during pregnancy that would be of interest to understand biological mechanisms. Also, there were unmeasured variables, like history of breast cancer, or other environmental factors that might be influencing the relationship, such as diet. On the other hand, we have longitudinal follow up that assessed the girls every six months during the pubertal time, which allowed us to determine pubertal events and progression with a better diagnosis and precision. Additionally, we used a novel approach to assess BD at young ages that is associated with a very low dose of radiation and that does not compress the breast. Finally, we evaluated BD in the daughters at the end of puberty, the time at which BD is highest and other determinants have not modified it during the life course.

Our study showed that maternal EGWG, according to 2009 IOM recommendation, increases AFGV in girls of medium-low socioeconomic level at Tanner B4 even after adjusting for potential confounding variables. However further follow up studies are needed to assess the association between EGWG and daughter's breast cancer risk.

In Chile, we have a high prevalence of overweight and obesity during pregnancy (61\%), which is an important public health concern because it affects not only the health of the mother but also that of the offspring. We were able to evaluate the effect of an EGWG in the medium term; however, it is necessary to continue the follow-up to see the future effects on the daughter's health.

\section{Methods}

Study design. This study was designed as part of the Growth and Obesity Chilean Cohort study (GOCs) and the DERCAM study ["Determinantes de Riesgo de Cáncer de Mama" (Determinants of Breast Cancer Risk)]. Briefly, the GOCs is a Chilean cohort of 1190 , who are representative of low and middle socioeconomic level children $^{33}$. They were recruited in 2006 (mean age 3.7y) while they were attending the National Nursery Schools Council Program in the southeastern area of Santiago, Chile. The initial aim of the cohort was to assess growth and childhood obesity and their associations with metabolic and hormonal complications in normal birth weight children $^{34}$. The inclusion criteria were children born between 2002 and 2003, singleton birth, BW of 2.5 to $4.5 \mathrm{~kg}$ and absence of medical conditions that could interfere with growth (more details have been published previously $)^{34}$. Since 2006, the children were invited to INTA periodically for the performance of different measurements and follow-up. In 2010, the girls' mothers were invited to participate in the DERCAM study; we included only women who were premenopausal at recruitment with no history of breast cancer or other breast disease and who were not pregnant or breastfeeding (details of the study have been published elsewhere) ${ }^{35}$. We obtained complete data from 341 pairs of girls and their mothers of the 400 mothers who were recruited in 2010 . There were no significant differences between the excluded and included girls and their mothers according to the mother's GWG, maternal age of menarche, or the girls' anthropometric data.

The GOCS and DERCAM study protocols and the current study were approved by the Ethics Committee Board of the Institute of Nutrition and Food Technology, University of Chile (INTA) (see related manuscript files). We confirm that all methods were carried out in accordance with relevant guidelines and regulations. Informed consents approved by the ethical committee were taken from the parents or guardian (Legally Authorized Representatives) and girls gave their assent (see related manuscript files).

Girls' data collection. Sexual maturation. Since 2009, a trained dietitian assessed pubertal development every 6 months using the Tanner scale ${ }^{36}$. The assessment included inspection and palpation of the breasts to differentiate between breast Tanner stage 2 (B2) and lipomastia. There was high concordance between the trained dietitian and a pediatric endocrinologist (Kappa index $=0.9)^{37}$. 
Menarche was defined as the first bleeding or menstrual period. Menarche was assessed at all visits or by telephone through a questionnaire to differentiate menarche from other diagnoses, such as vaginal or urinary infection, or trauma, among others.

Anthropometry. Anthropometric data was assessed at the Tanner B4 visit by a trained dietitian using standardized protocols (ICC $\geq 0.75)^{33}$. Weight was measured with a portable scale, SECA model 770 (capacity of $200 \mathrm{~kg}$ precision of $0.1 \mathrm{~kg}$ ); height was measured with a stadiometer, HARPENDER model 603 (capacity $200 \mathrm{~cm}$, sensitivity $0.1 \mathrm{~cm}$ ); and waist circumference, defined as the midpoint between the last rib and the iliac crest, was measured with a tape, LUFKIN W606PM (capacity $200 \mathrm{~cm}$ and precision $0.1 \mathrm{~cm}$ ). We defined central obesity as a WC $>$ the $90^{\text {th }}$ percentile according to age of the girls (9 to $13 \mathrm{y}$ ). The cutoff points for $\mathrm{WC}>$ the $90^{\text {th }}$ percentile according to NHANES III were 73.6, 76.6, 79.7, 82.7, and $85.8 \mathrm{~cm}$ for girls from 9 to $13 \mathrm{y}$ old, respectively. Body mass index (BMI) was calculated as weight $(\mathrm{kg}) / \mathrm{height} \mathrm{t}^{2}\left(\mathrm{~m}^{2}\right)$, and we estimated the BMI Z-score according to the 2007 World Health Organization (WHO) data ${ }^{38}$.

BW was collected retrospectively from clinical records, and the quality of the BW data has been previously evaluated, indicating $<1 \%$ implausible values (GOCS protocol) ${ }^{39}$.

Breast composition assessment. At the Tanner B4 visit, girls were invited to receive a breast DXA scan in order to evaluate the absolute fibroglandular volume $\left(\mathrm{AFGV}, \mathrm{cm}^{3}\right)$, total breast volume $\left(\mathrm{BV}, \mathrm{cm}^{3}\right)$ and percentage of fibroglandular volume $(\% \mathrm{FGV}=\mathrm{AFGV} / \mathrm{BV}, \%)$. These measurements were carried out as defined by the protocol developed by Dr. John Shepherd (more details have been published elsewhere ${ }^{40}$ at INTA using a GE Lunar Prodigy Bone Densitometer (GE Healthcare). Measurements were calibrated using a N17NS phantom (a density step phantom of constant thickness consisting of seven steps of different fractions of breast fibroglandular tissue and adipose fat) to estimate AFGV and \%FGV. The DXA scans were performed by a single technician trained by Dr. John Shepherd according to the standardized protocol. Briefly, girls were positioned laying on the left side of their body (lateral decubitus) with their left forearm under their head and their right hand holding their right breast to remove it from the scanning zone of their left breast. After the left breast was scanned, the girls rolled over her back to facilitate the scanning of the right breast using the same protocol. We used the mean of the right and left breast to estimate \%FGV and AFGV for each girl. The total dose of radiation from the 3 scans was estimated as $45 \mathrm{uSv}$, which is approximately equivalent to 5 days of natural radiation. Raw images were saved in low and high energy, and AFGV and \%FGV were calculated using software from one of the investigators (Shepherd) with intra- and interrater readings all had ICC values greater than 0.9. Recently, Pereira et al. found that in 200 GOCs mothers, the precision of the DXA data after the repositioning of the left breast was $2.8 \%$, and the ICCs for $\%$ FGV and AFGV were $>0.9^{19}$.

Mothers' data collection. In 2007, the GOCs mothers were invited to INTA for an anthropometric assessment and to answer a questionnaire related to sociodemographic and gyneco-obstetric data. Mothers self-reported their pre- and post-gestational weight in kg. Height was evaluated at the time of the visit, using the same procedure as described above. Using the self-reported data, pre-gestational and post-gestational BMI was calculated. We defined GWG as the total pregnancy weight gain in kg. Additionally, based on the 2009 IOM recommendation we categorized the GWG in below, within and above the recommendation related to the pre-gestational weight $\mathrm{BMI}(\mathrm{WHO})^{6}$.

From 2011 to 2012, 402 mothers of GOCs girls were invited to receive a digital mammography [craniocaudal (CC) and mediolateral oblique (MLO) views] during the follicular phase of their menstrual cycle at a private clinic in Santiago. Raw images of both breasts were exported from the Hologic Selenia system (Marlborough, MA, USA), and AFGV and \%FGV were estimated using a fully automated computer-assisted method with VOLPARA software (version 1.4.2) (Matakina Technology, Wellington, New Zealand).

Statistical analysis. Descriptive statistics were used to characterize the predictor, confounder and outcome variables. Maternal GWG was categorized according to the pregestational nutritional status IOM 2009 guidelines: i) above GWG ii) within GWG iii) below GWG. We dichotomized GWG into two groups: i) EGWG according to pre-gestational nutritional status and ii) non EGWG (a GWG within or below the recommendations). Additionally, we used GWG in kilograms. The daughters' breast compositions (AFGV, \%FGV) were dichotomized according to their 80th percentile distribution.

Logistic regression models were used to estimate the ORs and 95\% CIs comparing the three categories of GWG using breast composition at Tanner 4 and below the recommendation as the reference group. Additionally, we assessed GWG as a dichotomous variable (EGWG vs non-EGWG), GWG in kilograms, and birth weight as determinants of breast composition data at Tanner B4 (\%AFGV and FGV). Models were adjusted for the daughter's BMI Z-score, the presence or absence of menarche (yes/no) at the Tanner B4 visit (DXA measurement visit), maternal parity ( 1 or $>1$ living birth), maternal education ( $>$ or $<12 y$ ), gestational diabetes mellitus (yes/no) and \%FGV measured by mammography from 2011-2012. Additionally, we adjusted for birth weight $(>$ or $<$ the $80^{\text {th }}$ percentile of the girls' distribution) and maternal pregestational nutritional status when we assessed GWG in $\mathrm{kg}$. The analysis was carried out in Stata version 13; results were considered significant if the p-value was $<0.05$.

\section{Data availability}

The datasets generated and/or analyzed during the current study are not publicly available, because the study is still ongoing, but are available from the corresponding author on reasonable request.

Received: 27 September 2019; Accepted: 21 March 2020;

Published online: 20 April 2020 


\section{References}

1. McCormack, V. A. \& dos Santos Silva, I. Breast density and parenchymal patterns as markers of breast cancer risk: a meta-analysis. Cancer Epidemiol Biomarkers Prev 15, 1159-1169, https://doi.org/10.1158/1055-9965.epi-06-0034 (2006).

2. Boyd, N. et al. Breast-tissue composition and other risk factors for breast cancer in young women: a cross-sectional study. Lancet Oncol 10, 569-580, https://doi.org/10.1016/s1470-2045(09)70078-6 (2009).

3. Novotny, R., Daida, Y., Morimoto, Y., Shepherd, J. \& Maskarinec, G. Puberty, body fat, and breast density in girls of several ethnic groups. Am J Hum Biol 23, 359-365, https://doi.org/10.1002/ajhb.21145 (2011).

4. M de Salud. Vigilancia del estado nutricional de la población bajo control y de la lactancia materna en el sistema público de salud de Chile. (Ministerio de Salud, Santiago, Chile, 2014).

5. Garmendia, M. L., Mondschein, S., Matus, O., Murrugarra, R. \& Uauy, R. Predictors of gestational weight gain among Chilean pregnant women: The Chilean Maternal and Infant Nutrition Cohort study. Health Care Women Int 38, 892-904, https://doi.org/10 $.1080 / 07399332.2017 .1332627$ (2017).

6. Institute of Medicine (US) and National Research Council (US) Committee to Reexamine IOM Pregnancy Weight Guidelines, R. K., Yaktine AL, editors. Weight Gain During Pregnancy: Reexamining the Guidelines. (National Academies Press (US)National Academy of Sciences., Washington (DC), 2009).

7. Barker, D. J. In utero programming of cardiovascular disease. Theriogenology 53, 555-574, https://doi.org/10.1016/s0093691x(99)00258-7 (2000).

8. Barker, D. J., Bull, A. R., Osmond, C. \& Simmonds, S. J. Fetal and placental size and risk of hypertension in adult life. BMJ 301, 259-262 (1990).

9. Catalano, P. M. \& Ehrenberg, H. M. The short- and long-term implications of maternal obesity on the mother and her offspring. Bjog 113, 1126-1133, https://doi.org/10.1111/j.1471-0528.2006.00989.x (2006).

10. Harder, T., Rodekamp, E., Schellong, K., Dudenhausen, J. W. \& Plagemann, A. Birth weight and subsequent risk of type 2 diabetes: a meta-analysis. Am J Epidemiol 165, 849-857, https://doi.org/10.1093/aje/kwk071 (2007).

11. Gluckman, P. D., Hanson, M. A., Cooper, C. \& Thornburg, K. L. Effect of in utero and early-life conditions on adult health and disease. N Engl J Med 359, 61-73, https://doi.org/10.1056/NEJMra0708473 (2008).

12. Schellong, K., Schulz, S., Harder, T. \& Plagemann, A. Birth weight and long-term overweight risk: systematic review and a metaanalysis including 643,902 persons from 66 studies and 26 countries globally. PLoS One 7, e47776, https://doi.org/10.1371/journal. pone.0047776 (2012).

13. Michels, K. B. et al. Maternal Anthropometry and Mammographic Density in Adult Daughters. Pediatrics 138, S34-s41, https://doi. org/10.1542/peds.2015-4268F (2016).

14. Sanderson, M. et al. Maternal factors and breast cancer risk among young women. Paediatr Perinat Epidemiol 12, 397-407, https:// doi.org/10.1046/j.1365-3016.1998.00133.x (1998).

15. Wilson, K. M., Willett, W. C. \& Michels, K. B. Mothers' pre-pregnancy BMI and weight gain during pregnancy and risk of breast cancer in daughters. Breast Cancer Res Treat 130, 273-279, https://doi.org/10.1007/s10549-011-1582-3 (2011).

16. Silva Idos, S., De Stavola, B. \& McCormack, V. Birth size and breast cancer risk: re-analysis of individual participant data from 32 studies. PLoS Med 5, e193, https://doi.org/10.1371/journal.pmed.0050193 (2008).

17. Xu, X. et al. Birth weight as a risk factor for breast cancer: a meta-analysis of 18 epidemiological studies. J Womens Health (Larchmt) 18, 1169-1178, https://doi.org/10.1089/jwh.2008.1034 (2009).

18. Denholm, R. et al. Pre-natal exposures and breast tissue composition: findings from a British pre-birth cohort of young women and a systematic review. Breast Cancer Res 18, 102, https://doi.org/10.1186/s13058-016-0751-z (2016).

19. Pereira, A. et al. Determinants of volumetric breast density in Chilean premenopausal women. Breast Cancer Res Treat 162, 343-352, https://doi.org/10.1007/s10549-017-4126-7 (2017).

20. Shepherd, J. A. et al. Clinical comparison of a novel breast DXA technique to mammographic density. Med Phys 33, 1490-1498, https://doi.org/10.1118/1.2193691 (2006).

21. Goldstein, R. F. et al. Association of Gestational Weight Gain With Maternal and Infant Outcomes: A Systematic Review and Metaanalysis. Jama 317, 2207-2225, https://doi.org/10.1001/jama.2017.3635 (2017).

22. Catalano, P. M., Presley, L. \& Minium, J. \& Hauguel-de Mouzon, S. Fetuses of obese mothers develop insulin resistance in utero. Diabetes Care 32, 1076-1080, https://doi.org/10.2337/dc08-2077 (2009).

23. Ferraro, Z. M., Qiu, Q., Gruslin, A. \& Adamo, K. B. Excessive gestational weight gain and obesity contribute to altered expression of maternal insulin-like growth factor binding protein-3. Int J Womens Health 5, 657-665, https://doi.org/10.2147/ijwh.s49594 (2013).

24. Berglund, S. K. et al. Maternal, fetal and perinatal alterations associated with obesity, overweight and gestational diabetes: an observational cohort study (PREOBE). BMC Public Health 16, 207, https://doi.org/10.1186/s12889-016-2809-3 (2016).

25. Walsh, J. M., McGowan, C. A., Mahony, R. M., Foley, M. E. \& McAuliffe, F. M. Obstetric and metabolic implications of excessive gestational weight gain in pregnancy. Obesity (Silver Spring) 22, 1594-1600, https://doi.org/10.1002/oby.20753 (2014).

26. Vidal, A. C. et al. Maternal BMI, IGF-I Levels, and Birth Weight in African American and White Infants. Int J Pediatr 2013, 191472, https://doi.org/10.1155/2013/191472 (2013).

27. Schubring, C. et al. Levels of leptin in maternal serum, amniotic fluid, and arterial and venous cord blood: relation to neonatal and placental weight. J Clin Endocrinol Metab 82, 1480-1483, https://doi.org/10.1210/jcem.82.5.3935 (1997).

28. Kaar, J. L. et al. Leptin levels at birth and infant growth: the EPOCH study. J Dev Orig Health Dis 5, 214-218, https://doi.org/10.1017/ s204017441400021x (2014).

29. Koistinen, H. A. et al. Leptin concentration in cord blood correlates with intrauterine growth. J Clin Endocrinol Metab 82, 3328-3330, https://doi.org/10.1210/jcem.82.10.4291 (1997).

30. Wuu, J. et al. Correlates of pregnancy oestrogen, progesterone and sex hormone-binding globulin in the USA and China. Eur J Cancer Prev 11, 283-293, https://doi.org/10.1097/00008469-200206000-00012 (2002).

31. Trichopoulos, D. Intrauterine environment, mammary gland mass and breast cancer risk. Breast Cancer Res 5, 42-44, https://doi. org/10.1186/bcr555 (2003).

32. Savarese, T. M. et al. Correlation of umbilical cord blood hormones and growth factors with stem cell potential: implications for the prenatal origin of breast cancer hypothesis. Breast Cancer Res 9, R29, https://doi.org/10.1186/bcr1674 (2007).

33. Kain, J., Corvalan, C., Lera, L., Galvan, M. \& Uauy, R. Accelerated growth in early life and obesity in preschool Chilean children. Obesity (Silver Spring) 17, 1603-1608, https://doi.org/10.1038/oby.2009.37 (2009).

34. Corvalán, C., Uauy, R., Stein, A. D., Kain, J. \& Martorell, R. Effect of growth on cardiometabolic status at 4 y of age. Am J Clin Nutr 90, 547-555, https://doi.org/10.3945/ajcn.2008.27318 (2009).

35. Garmendia, M. L., Alonso, F. T., Kain, J., Uauy, R. \& Corvalan, C. Alarming weight gain in women of a post-transitional country. Public Health Nutr 17, 667-673, https://doi.org/10.1017/s1368980013000098 (2014).

36. Marshall, W. A. \& Tanner, J. M. Variations in pattern of pubertal changes in girls. Arch Dis Child 44, 291-303 (1969).

37. Pereira, A. et al. Breast bud detection: a validation study in the Chilean growth obesity cohort study. BMC Womens Health 14, 96, https://doi.org/10.1186/1472-6874-14-96 (2014).

38. de Onis, M. et al. Development of a WHO growth reference for school-aged children and adolescents. Bull World Health Organ $\mathbf{8 5}$, 660-667 (2007). 
39. Kain, J. et al. [Evolution of the nutritional status of Chilean children from preschool to school age: anthropometric results according to the source of the data]. Arch Latinoam Nutr 60, 155-159 (2010).

40. Shepherd, J. A., Kerlikowske, K. M., Smith-Bindman, R., Genant, H. K. \& Cummings, S. R. Measurement of breast density with dual X-ray absorptiometry: feasibility. Radiology 223, 554-557, https://doi.org/10.1148/radiol.2232010482 (2002).

\section{Acknowledgements}

We thank all the GOCS participants who continue supporting our work since 2006 and our funding sources, including the Chilean Council for Science and Technology: FONDECYT 11170670, PCI Proyecto REDI170060, the World Cancer Research Fund (grant 2010/245), the National Institute of Health (NIH R01), and the National Cancer Institute, (Grant No 5R01CA158313).

\section{Author contributions}

A.P., C.C. and M.L.G. participated in study design; A.P. and A.L. conducted the statistical analyses, interpreted the results and co-write the manuscript; JS oversaw the breast composition measurements and interpretation; M.L.G., C.C. and K.M. contributed in the analysis and interpretation of the data; M.L.G., C.C., J.S. and K.M. provided critical revision of the manuscript for important intellectual content. All authors read and approved the final manuscript.

\section{Competing interests}

The authors declare no competing interests.

\section{Additional information}

Supplementary information is available for this paper at https://doi.org/10.1038/s41598-020-63260-9.

Correspondence and requests for materials should be addressed to A.P.

Reprints and permissions information is available at www.nature.com/reprints.

Publisher's note Springer Nature remains neutral with regard to jurisdictional claims in published maps and institutional affiliations.

(c) (1) Open Access This article is licensed under a Creative Commons Attribution 4.0 International License, which permits use, sharing, adaptation, distribution and reproduction in any medium or format, as long as you give appropriate credit to the original author(s) and the source, provide a link to the Creative Commons license, and indicate if changes were made. The images or other third party material in this article are included in the article's Creative Commons license, unless indicated otherwise in a credit line to the material. If material is not included in the article's Creative Commons license and your intended use is not permitted by statutory regulation or exceeds the permitted use, you will need to obtain permission directly from the copyright holder. To view a copy of this license, visit http://creativecommons.org/licenses/by/4.0/.

(C) The Author(s) 2020 